\title{
DeloRes trial: study protocol for a randomized trial comparing two standardized surgical approaches in rectal prolapse - Delorme's procedure versus resection rectopexy
}

\author{
Simone Rothenhoefer ${ }^{1 \dagger}$, Florian Herrle ${ }^{1 \dagger}$, Alexander Herold ${ }^{2}$, Andreas Joos $^{2}$, Dieter Bussen ${ }^{2}$, Meinhard Kieser ${ }^{3}$,
} Petra Schiller ${ }^{3}$, Christina Klose ${ }^{3}$, Christoph M Seiler ${ }^{4}$, Peter Kienle ${ }^{1}$ and Stefan Post ${ }^{1 *}$

\begin{abstract}
Background: More than 100 surgical approaches to treat rectal prolapse have been described. These can be done through the perineum or transabdominally. Delorme's procedure is the most frequently used perineal, resection rectopexy the most commonly used abdominal procedure. Recurrences seem more common after perineal compared to abdominal techniques, but the latter may carry a higher risk of peri- and postoperative morbidity and mortality.

Methods/Design: DeloRes is a randomized, controlled, observer-blinded multicenter trial with two parallel groups. Patients with a full-thickness rectal prolapse (third degree prolapse), considered eligible for both operative methods are included. The primary outcome is time to recurrence of full-thickness rectal prolapse during the 24 months following primary surgery. Secondary endpoints are time to and incidence of recurrence of full-thickness rectal prolapse during the 5-year follow-up, duration of surgery, morbidity, hospital stay, quality of life, constipation, and fecal incontinence. A meta-analysis was done on the basis of the available data on recurrence rates from 17 publications comprising 1,140 patients. Based on the results of a meta-analysis it is assumed that the recurrence rate after 2 years is 20\% for Delorme's procedure and 5\% for resection rectopexy. Considering a rate of lost to follow-up without recurrence of $30 \%$ a total of 130 patients $(2 \times 65$ patients) was calculated as an adequate sample size to assure a power of $80 \%$ for the confirmatory analysis.
\end{abstract}

Discussion: The DeloRes Trial will clarify which procedure results in a smaller recurrence rate but also give information on how morbidity and functional results compare.

Trial registration: German Clinical Trial Number DRKS00000482

Keywords: Rectal prolapse, Surgery, Delorme's procedure, Resection rectopexy, Recurrence

\section{Background}

Full-thickness prolapse of the rectum is defined as protrusion of the full thickness of the rectal wall through the anus. There is a peak in the incidence of this disease in the seventh decade of life. A total of $80 \%$ to $95 \%$ of the patients are women [1,2]. The etiology of rectal

\footnotetext{
* Correspondence: Stefan.post@umm.de

${ }^{\dagger}$ Equal contributors

'Department of Surgery|, University Medical Centre Mannheim (UMM), University of Heidelberg, Heidelberg, Germany

Full list of author information is available at the end of the article
}

prolapse is still unknown. Fifty percent to seventy percent of patients complain of longstanding constipation, the rate of fecal incontinence ranges between $40 \%$ and $80 \%$ [3-6]. Other predisposing conditions include chronic straining defecation, pregnancy, previous surgery, and neurological disease. There is probably a genetic disposition to this condition.

Treatment of rectal prolapse is usually surgical. More than 100 surgical approaches have been described in the literature. The aims of the operation are to correct the rectal prolapse, to restore normal bowel function, and to avoid a

\section{C) Biomed Central}

(c) 2012 Rothenhoefer et al.; licensee BioMed Central Ltd. This is an Open Access article distributed under the terms of the Creative Commons Attribution License (http://creativecommons.org/licenses/by/2.0), which permits unrestricted use, distribution, and reproduction in any medium, provided the original work is properly cited. 
recurrence of full-thickness rectal prolapse. For many patients, constipation and fecal incontinence improve after surgery $[4,7,8]$.

Basically, two different surgical approaches can be distinguished: perineal and transabdominal procedures. In general, perineal surgical repairs supposedly cause less morbidity and mortality compared with abdominal operations $[7,9,10]$. They are considered especially indicated in the elderly and/or high-risk patients as they can also be done in spinal or epidural anesthesia $[9,11,12]$. On the other hand, recurrences seem more frequent after perineal techniques than after abdominal operations [1-3,13]. Abdominal repairs involve fixing the rectum to the sacrum by using either mesh or sutures. In addition to rectopexy a sigmoid resection is commonly performed. Laparoscopic repair of rectal prolapse has similar morbidity and recurrence rates as open surgery [7,14]. There are data suggesting that the laparoscopic compared to the conventional approach has short-term benefits as described for other laparoscopic abdominal procedures (reduced length of hospital stay, less postoperative pain, faster return to normal bowel function, and less wound complications) $[9,15]$. But when using a modern fast-track regime (involving multimodal balanced anesthesia and analgesia including peridural catheter, early normal nutrition and mobilization as well as avoidance of tubes and catheters) the advantages of a laparoscopic approach have become somewhat less clear [15-17]. In general the fast-track regime allows enhanced recovery and discharge of patients compared to conventional postoperative management. Application of such a fast-track regime allows compensation of assumed disadvantages like more pain or slower mobilization of patients after open abdominal surgery compared to laparoscopic surgery.

In conclusion, perineal as well as abdominal (mostly laparoscopic) procedures remain the established options in the surgical treatment of rectal prolapse without evidence from adequately designed randomized studies which of these procedures are superior. There are only insufficient data available on the long-term benefits and risks, quality of life, and total treatment costs. Our trial aims to contribute to the very scarce high-level-evidence basis of randomized trials comparing a perineal $v s$. an abdominal approach. The urgent need for a randomized trial such as DeloRes was also pointed out in the Cochrane Review by Tou in 2009 [18].

\section{Methods/Design}

\section{Trial design}

DeloRes is a randomized, controlled, observer-blinded multicenter trial with two parallel groups.

\section{Patient population \\ Inclusion criteria}

- Full-thickness rectal prolapse, externally visible on straining

- ASA-Score I-III

- Patient is suited for both standardized surgical approaches

- Patient is able to cooperate

- Patient has given written informed consent

- Aged 18 years or older

\section{Exclusion criteria}

- Recurrence of full-thickness rectal prolapse

- Patient with stoma

- Patient with inflammatory bowel disease

- Pregnancy or breastfeeding

- Patient currently under chemotherapy

- Active malignant disease and life expectancy less than 24 months

- Body mass index greater than 40

- Participation in another intervention trial with interference of intervention and outcome of this study

The aim was to exclude as few patients as possible, but nevertheless minimize attrition bias in long-term follow-up and enable a high recruitment rate given the fact that patients presenting with full rectal prolapse are a small population of a reasonably higher population of patients not willing to present at their physicians because of misinformation or shame.

Thus patients with recurrent rectal prolapse would often not be acceptable for surgeons to be randomized to perineal vs. abdominal approach especially if the prior surgery had been a perineal approach. Patients not surviving at least 24 months would not be available for the primary endpoint visit at 24 months postoperatively. And patients with $\mathrm{BMI}>40$ had been excluded as they are very few and do not represent the common patient habitus of rectal prolapse.

\section{Scheme of intervention}

DeloRes will be performed in 13 trial centers. All participating centers are cooperating units with a special focus on colorectal surgery and all centers perform between eight and sixty surgical interventions for rectal prolapse per year. In order to minimize performance bias, only surgeons with an adequate experience in performing the approaches investigated operate on patients in this study (minimum number of procedures performed ('life-time experience'): Delorme's procedure $=20$, (laparoscopic) resection rectopexy $=20$ ). Each study center provides at 
least one surgeon with the required experience for Delorme's procedure and one surgeon with the required experience for (laparoscopic) resection rectopexy (expertise based, best team approach). To ensure standardization for all participating centers an operative manual with standardized video sequences will be prepared. Moreover, consented crucial steps of each procedure will be captured in the clinical record file. In addition, in order to allow confirmation of a certain procedure quality, selected digital photos will be taken.

To reflect current practice and to increase external validity of the trial, perioperative standards (for example, bowel preparation, parenteral nutrition, fast-track, postoperative application of laxatives) will not be strictly standardized. Each trial center, however, will document its own standards in a short questionnaire and agrees not to change this standard during trial recruitment.

\section{Recruitment and trial timeline}

Recruitment of participants started in September 2010. The duration of the trial for each patient is expected to be 60 months with follow-up at 6, 12, 24, and 60 months after the primary surgery.

\section{Treatment assignment and randomization}

Consecutively screened and eligible patients will be included in the trial. In order to achieve comparable intervention groups, patients will be allocated by preoperative randomization 24 to $48 \mathrm{~h}$ prior to surgery after given written informed consent using a centralized web based tool (www.randomizer.at). Block randomization stratified by center will be applied to achieve equal group sizes per center.

\section{Interventions and trial flow}

The laparoscopic approach is considered the standard approach for the transabdominal operation of full-thickness rectal prolapse. Laparoscopic resection rectopexy is suggested to yield better results in the early postoperative phase in comparison to the open approaches with equal recurrence rates in comparison to the open approach. However, the advantages of a laparoscopic approach become somewhat less evident under a fast-track regime, therefore open resection rectopexy is also acceptable via a Pfannenstiel incision. The latter approach has proven to be only moderately invasive in numerous procedures of the lower abdomen. The most frequently used perineal procedure is Delorme's procedure, which shows low postoperative morbidity. The trial flow is illustrated in Figure 1.

\section{Description of trial days}

All patients will be informed about the purpose of the trial and surgical treatment modalities comprising their benefits as well as risks. The schedule of trial interventions is presented in Table 1 .

\section{Outcome measures and definitions}

The clinically most relevant parameter in the treatment of full-thickness rectal prolapse is the time to recurrence. Therefore this parameter is defined as primary outcome measure, evaluated during the 24 months following primary surgery. Recurrence is defined as the circular protrusion of rectal mucosa through the anal canal and will be examined by standardized history, clinical examination, and photo documentation. To assess the primary outcome, patients are asked to perform a straining maneuver in a sitting position (patients not able to sit will be assessed in a lateral decubitus position). Then a photograph is taken during straining. The primary outcome is finally determined by the independent review board on the basis of the photograph.

Secondary endpoints are time to and incidence of recurrence of full-thickness rectal prolapse during 5-year follow-up, duration of surgical intervention, morbidity, SAE, all causes of mortality within 3 months after primary surgery (this period was chosen to get any mortality possible related to surgery. Patients with rectal prolapse are usually rather old and frail. There are multiple reasons for further morbidity or mortality which are expected to be unrelated to the surgical procedure in case they occur beyond the first 3 months), length of initial hospital stay, reoperation rate for recurrent prolapse, cumulative hospital stay and change in quality of life, constipation, and fecal incontinence as measured by appropriate questionnaires.

The time to and the incidence of recurrence of fullthickness rectal prolapse during a 5-year follow-up after primary surgery will be assessed as explained above. Morbidity occurring during the primary hospital stay is further differentiated into surgical and non-surgical complications, which are specifically defined as following: severity grading is done with the Clavien classification [19] and for anastomotic leakage with the classification of the International Study Group of Rectal Cancer [20]. The definitions of the secondary outcomes are shown in Table 2.

\section{Data management}

All protocol-required information collected during the trial must be documented in the paper-based CRF by the investigator. Any outstanding entries must be completed immediately after the final examination. The completed CRF must be reviewed and signed by the investigator named in the trial protocol.

In order to ensure that the database reproduces the CRFs correctly a double entry of data will be performed by two different people. 


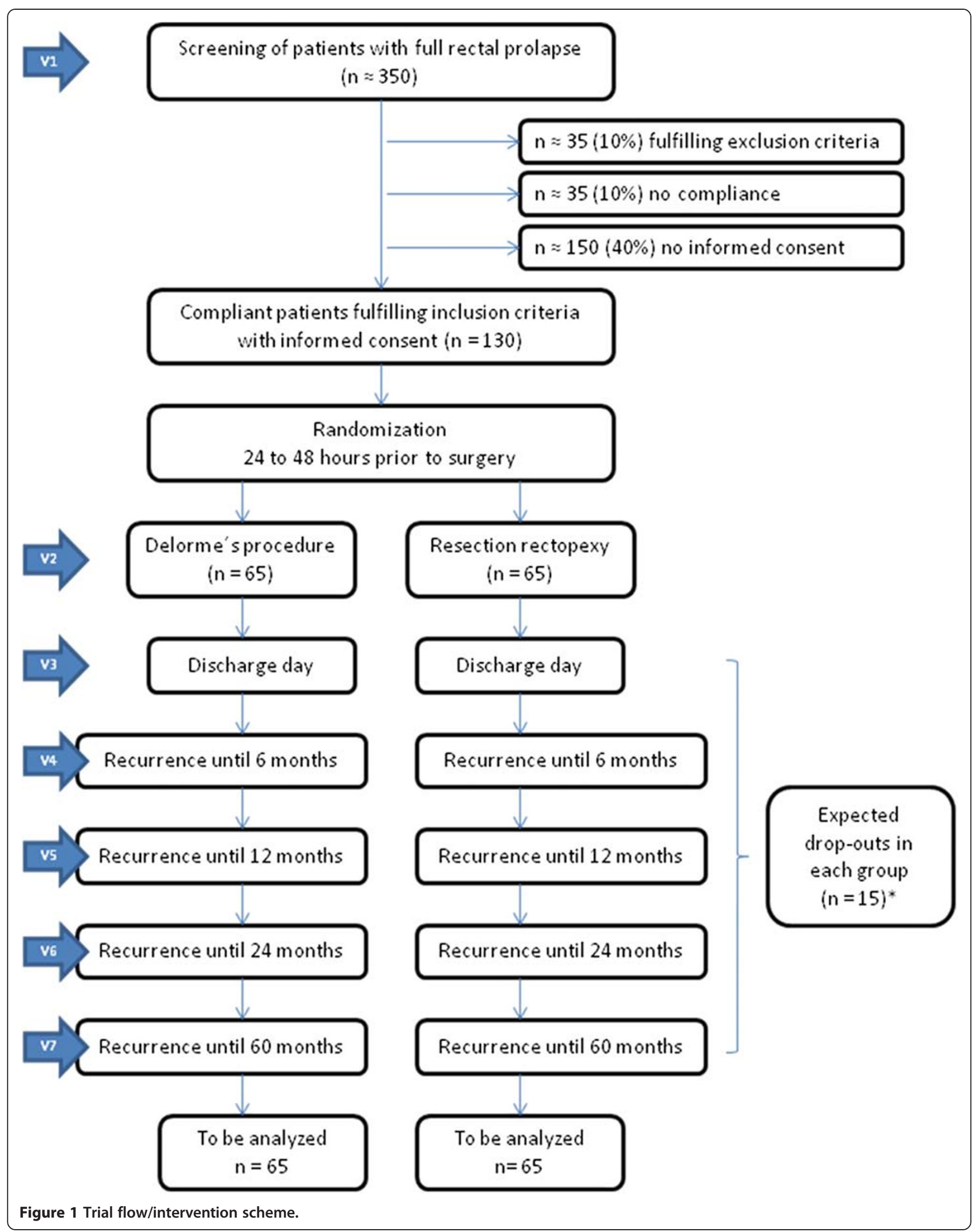


Table 1 Study visits of DeloRes

\begin{tabular}{|c|c|c|c|c|c|c|c|}
\hline & Visit 1 & Visit 2 & Visit 3 & Visit 4 & Visit 5 & Visit 6 & Visit 7 \\
\hline & Screening & Surgery & $\begin{array}{c}\text { Day of } \\
\text { Discharge }\end{array}$ & $\begin{array}{c}6 \text { months } \\
\text { after Surgery }\end{array}$ & $\begin{array}{c}12 \text { months after } \\
\text { Surgery }\end{array}$ & $\begin{array}{l}24 \text { months } \\
\text { after Surgery }\end{array}$ & $\begin{array}{l}60 \text { months } \\
\text { after Surgery }\end{array}$ \\
\hline $\begin{array}{l}\text { Demographic and } \\
\text { clinical baseline data }\end{array}$ & $x$ & & & & & & \\
\hline Inclusion/Exclusion & $x$ & & & & & & \\
\hline Randomization & $x$ & & & & & & \\
\hline Intervention & & $x$ & & & & & \\
\hline $\begin{array}{l}\text { Assessment of } \\
\text { Complications and Safety }\end{array}$ & & $x$ & $\times$ & $x$ & $x$ & $x$ & $x$ \\
\hline Recurrence & & & & $x^{a}$ & $x^{a}$ & $x$ & $x$ \\
\hline Secondary endpoints & & $x$ & $x$ & $x^{a}$ & $x^{a}$ & $x$ & \\
\hline SF-12 & $x$ & & & $x^{a}$ & $x^{a}$ & $x$ & \\
\hline $\begin{array}{l}\text { Herold } \\
\text { constipation score }\end{array}$ & $x$ & & & $x^{a}$ & $x^{a}$ & $x$ & \\
\hline Wexner score & $x$ & & & $x^{a}$ & $x^{a}$ & $x$ & \\
\hline Rockwood-FIQLScore & $x$ & & & $x^{a}$ & $x^{a}$ & $x$ & \\
\hline
\end{tabular}

\section{Compliance/rate of loss to follow-up}

To reduce the number of patients not able or willing to visit the study centers a study nurse will be appointed to visit the patients and to assess the outcome at the specified time ('flying study-nurse'). Furthermore, the timeto-event method will be applied for the primary analysis to allow for all available information including the observation time of patients who drop out early. Nevertheless, an additional percentage of patients will be recruited to assure a sufficient power for the confirmatory analysis.

\section{Safety assessments and reporting of adverse events}

Analysis of safety-related data is performed with respect to frequency of serious adverse events, frequency of serious adverse events stratified by intensity and causality, and frequency of morbidity in both treatment groups.

From the day of randomization until the regular end of trial follow-up or until premature withdrawal of the patient, all serious adverse events must be documented on a 'serious adverse event form' available in the investigator site file.

A serious adverse event will be defined as an event that results in death, is immediately life-threatening, requires or prolongs hospitalization beyond the 20th postoperative day for any medical reason, requires readmission for any medical reason within 3 months after the operation within this trial, requires readmission for treatment of surgical complications related to the study operation beyond 3 months postoperatively, or results in persistent or significant disability or incapacity. Serious adverse events will be classified in intensity (mild, moderate, severe), outcome (recovered completely, recovered with sequelae, not recovered, death, unknown), and causality (unrelated, possibly related, probably related, definitely related, not assessable).

The assessment is based on surgical findings and the clinical course of the patient. It needs to be done by the investigators. Serious adverse events have to be reported by the attending physician to the coordinating investigator or one of both study supervisors within $24 \mathrm{~h}$ after the SAE becomes known.

\section{Statistical methods}

\section{Sample size calculation}

The sample size calculation is based on the analysis of the primary endpoint (time to recurrence of fullthickness rectal prolapse during a 2-year follow-up). A meta-analysis including 17 publications (Delorme [2,5,6,8,9,12,13,25]; (Laparoscopic) Resection Rectopexy $[1,3,4,7,14,26-28])$ showed recurrence rates ranging from $10 \%$ to $30 \%$ (Delorme's procedure) and from $0 \%$ to $11 \%$ (laparoscopic resection rectopexy) (Table 3). Based on these data, we assume a recurrence rate 2 years after randomization of $20 \%$ for the Delorme's procedure and $5 \%$ for resection rectopexy, respectively. If the unstratified two-sided log rank test at level of significance $\alpha=5 \%$ was applied $2 \times 50=100$ patients would be required to achieve a power of 1 - beta $=80 \%$ (nQueryAdvisorR 7.0, [29]). It is expected that the rate of loss to follow-up without recurrence of full-thickness rectal prolapse will add up to $30 \%$. Even though the lack of information on the primary endpoint at 2 years for these patients is partly addressed by the applied time-to-event method, another $30 \%$ of patients will be randomized to compensate for this partial loss of information. It can be expected that application of the center-stratified version 
Table 2 Definitions of secondary outcomes

\begin{tabular}{|c|c|}
\hline \multicolumn{2}{|l|}{ Surgical complications } \\
\hline Postoperative ileus & $\begin{array}{l}\text { Obstructive or paralytic symptoms after surgery with the need to suspend food } \\
\text { intake and/or insert a gastric tube; this has to be confirmed radiologically (by abdominal sonography } \\
\text { or plain abdominal X-ray or CT scan) }\end{array}$ \\
\hline Postoperative hemorrhage & $\begin{array}{l}\text { Need for administration of two or more red cell concentrates within the first } 24 \mathrm{~h} \text { postoperatively } \\
\text { or need for reoperation }\end{array}$ \\
\hline Surgical site infection & CDC definition [21] \\
\hline Intra-abdominal abscess & $\begin{array}{l}\text { Intra-abdominal collection of purulent or infected fluid (confirmed by culture) confirmed by } \\
\text { puncture or by surgical reintervention }\end{array}$ \\
\hline Anastomotic leakage & $\begin{array}{l}\text { Grade A-C, Definition of grade according to International Study Group of Rectal Cancer 2010, } \\
\text { diagnosed by CT scan with radiographic enema, endoscopy, drain secretion (stool) or reoperation }\end{array}$ \\
\hline \multicolumn{2}{|l|}{ Non-surgical complications } \\
\hline Thrombosis & $\begin{array}{l}\text { Clinical evidence (for example, pain, swelling, warmth, erythema) of a leg or pelvic vein thrombosis } \\
\text { confirmed by duplex sonography or } C T \text { angiography, which was not previously known }\end{array}$ \\
\hline Pulmonary embolism & $\begin{array}{l}\text { Clinical (for example, tachycardia, dyspnea) and/or radiological evidence of pulmonary embolism } \\
\text { confirmed by spiral CT or lung perfusion scintigram }\end{array}$ \\
\hline \multirow[t]{6}{*}{ Postoperative pulmonary infection } & At least three of the following: \\
\hline & - temperature $>38^{\circ} \mathrm{C}$ \\
\hline & - purulent tracheal secretion \\
\hline & - leucocytes >12 or < 4.5 [10E9/L] \\
\hline & - elevated CRP \\
\hline & AND Evidence for pulmonary infection radiologically \\
\hline Renal failure & Need for dialysis or hemofiltration \\
\hline Cerebral insult & $\begin{array}{l}\text { Ischemic or non-ischemic cerebrovascular event with persistent paresis or paralysis without previous } \\
\text { history confirmed by CT or MRT }\end{array}$ \\
\hline Myocardial infarction & $\begin{array}{l}\text { Electrocardiogram (NSTEMI or STEMI) and enzyme (Troponin I) changes suggestive of myocardial } \\
\text { infarction or needing admission to coronary care unit }\end{array}$ \\
\hline Serious adverse events & SAE occurring from the day of randomization until regular end of trial follow-up or withdrawal \\
\hline Mortality & All causes of mortality within 3 months after primary surgery \\
\hline $\begin{array}{l}\text { Duration of surgical } \\
\text { intervention }\end{array}$ & $\begin{array}{l}\text { First incision to the completion of skin closure (resection rectopexy) or the last coloanal suture } \\
\text { (Delorme's procedure) }\end{array}$ \\
\hline Length of initial hospital stay & $\begin{array}{l}\text { Means the hospitalization period from the primary operation date until the day of discharge } \\
\text { (= postoperative hospital stay) }\end{array}$ \\
\hline Reoperation rate for recurrent prolapse & Any surgical intervention for a recurrence \\
\hline Cumulative hospital stay & $\begin{array}{l}\text { Defined by the days in hospital after the primary surgery as well as the following hospitalizations } \\
\text { due to complications or recurrence within } 24 \text { months after the primary operation }\end{array}$ \\
\hline \multicolumn{2}{|c|}{ Change of quality of life, constipation and incontinence } \\
\hline & $\begin{array}{l}\text { Measured by means of the appropriate questionnaires SF-12, ([22], validated in German), } \\
\text { Herold constipation score ([23], evaluated in German, but not yet published), Wexner-Score ([10], } \\
\text { non-validated in German, most commonly used score) and Rockwood-FIQLScore ([24], validated), } \\
\text { prior to the surgical intervention as well as 6, 12, and } 24 \text { months after the intervention }\end{array}$ \\
\hline
\end{tabular}

of the log rank test will further increase the power. Based on these considerations, a total of 130 patients ( $2 \times 65$ patients) will be allocated to the trial which should be sufficient to assure a power of $80 \%$ for the confirmatory analysis.

\section{Analysis}

The allocation of all patients to the different analysis populations will be defined prior to the analysis (full analysis set (FAS) according to the intention-to-treat principle (ITT; all randomized patients as randomized), per protocol (PP) analysis set, safety analysis set). The procedure of allocation will be documented in the statistical analysis plan. During the data review, deviations from the protocol will be assessed as 'minor' or 'major'. Major deviations from the protocol will lead to the exclusion of a patient from the PP analysis set.

The confirmatory analysis is performed for the full analysis set. The null-hypothesis 'no difference in the time to recurrence of full-thickness rectal prolapse between experimental and control intervention during the 2-year follow-up after randomization' is tested by 
Table 3 Literature review for sample size calculation

\begin{tabular}{|c|c|c|c|c|c|}
\hline \multicolumn{6}{|c|}{ Delorme's procedure } \\
\hline Author et al. & $\begin{array}{l}\text { Patients } \\
(\mathrm{m} / \mathrm{f})\end{array}$ & Study design & $\begin{array}{l}\text { Recurrences } \\
\text { (\%) }\end{array}$ & $\begin{array}{l}\text { Improvement } \\
\text { incontinence \% }\end{array}$ & $\begin{array}{l}\text { Improvement } \\
\text { obstipation \% }\end{array}$ \\
\hline Senapati (1994) & $32(8 / 24)$ & Retrospective & 12.5 & 41 & 16 \\
\hline Oliver (1994) & $40(5 / 35)$ & Retrospective & 22 & 68 & n.s. \\
\hline Tobin (1994) & $49(6 / 43)$ & Prospective & 26 & 50 & n.s. \\
\hline Lechaux (1995) & $85(8 / 77)$ & Retrospective & 13.5 & 69 & n.s. \\
\hline Pescatori (1998) & 33 & Retrospective & 21 & n.s. & n.s. \\
\hline Watts (2000) & $101(10 / 91)$ & Retrospective & 30 & 89 & 44 \\
\hline Watkins (2003) & $52(6 / 46)$ & Retrospective & 10 & 58 & n.s. \\
\hline Tsunoda (2003) & $31(7 / 24)$ & Retrospective & 13 & 63 & 38 \\
\hline Marchal (2005) & $60(7 / 53)$ & Retrospective & 23 & 42 & 54 \\
\hline
\end{tabular}

(Laparoscopic) Resection rectopexy

\begin{tabular}{llllll}
\hline Author et al. & $\begin{array}{l}\text { Patients } \\
\text { (m/f) }\end{array}$ & Study design & $\begin{array}{l}\text { Recurrences } \\
\mathbf{( \% )}\end{array}$ & $\begin{array}{l}\text { Improvement } \\
\text { incontinence \% }\end{array}$ & $\begin{array}{l}\text { Improvement } \\
\text { obstipation \% }\end{array}$ \\
\hline Huber (1995) & $42(2 / 40)$ & Prospective & 0 & 65 & 41 \\
\hline Stevenson (1998) & $30(1 / 29)$ & Prospective & 0 & 70 & 64 \\
\hline Bruch (1999) & $72(4 / 68)$ & Prospective & 0 & 64 & 46 \\
\hline Kim (1999) & $176(16 / 160)$ & Retrospective & 5 & 55 & 67 \\
\hline Kellokumpu (2000) & $34(3 / 31)$ & Prospective & 7 & n.s. & n.s. \\
\hline Carpelan (2005) & $75(11 / 64)$ & Retrospective & 3 & n.S. & 69 \\
\hline Ashari (2005) & $117(1 / 116)$ & Prospective & 2.5 & 62 & n.s. \\
\hline Kariv (2005) & $111(14 / 97)$ & Prospective & 11 & n.s. & \\
\hline ns.
\end{tabular}

n.s., Not specified.

application of the log rank test stratified by center at the two-sided level $\alpha=5 \%$. Drop-out and lost-to-follow-up without recurrence of full-thickness rectal prolapse are considered as censoring events.

For the analysis of the secondary outcomes descriptive methods will be used, including the calculation of appropriate summary methods for the empirical distribution as well as calculation of descriptive two-sided $P$ values for comparisons of treatment groups. A special focus of the exploratory analyses will be on the time course of the primary as well as the secondary endpoints. Additionally, sensitivity analyses will be conducted for different study populations (per protocol population, appropriate subgroups). Further exploratory analyses will be performed to identify potential prognostic factors for the intervention effect. The time to recurrence of full-thickness rectal prolapse will additionally be analyzed applying a Cox regression model that includes covariates of potential prognostic value.

The safety analysis is based on all randomized patients who were treated with the interventions under investigation. The analysis includes calculation and comparison of the rates of specified complications (see secondary endpoints) and serious adverse events as well as of severity and relationship to intervention and graphical display of the time course. Furthermore, statistical methods are used to assess the quality of data and the homogeneity of intervention groups.

All analyses will be done using SAS version 9.1 or higher.

\section{Withdrawals}

Participants are allowed to withdraw their written informed consent for the trial at any time and without giving reasons for their decision. If investigators or members of the independent Data Monitoring and Safety Board raise any concerns on an individual patient's safety, the patient will be withdrawn from the trial.

\section{Stopping guidelines}

The surgical interventions applied in this trial are clinically established standard methods for the treatment of rectal prolapse. Therefore, SAEs that will cause a premature end of the trial are not anticipated.

The DSMB will be informed about the recruitment and relevant safety data in regular time intervals. If any safety concerns arise, the DSMB members will confer on the continuation of the trial and can recommend stopping of the trial. The Ethic Committees then have to be informed. 


\section{Trial organization and administration \\ Funding}

DeloRes is funded by the German Research Foundation (Deutsche Forschungsgemeinschaft, DFG).

\section{Monitoring}

Clinical monitoring will be performed by an institution which is independent from other trial staff and experienced due to participation in many other surgical trials. Monitoring procedures will be adapted to the study specific risks for the patients and standard operating procedures (SOP) will be implemented to ensure patients safety and integrity of the clinical data, for example, primary endpoint in adherence to study protocol. Pre-study visits will be performed in centers interested in participating in the study in order to ensure high compliance quality of the participating centers concerning, for example, patient recruitment and documentation. Prior to study start, all participating centers will be personally trained and introduced into all study specific procedures during individual on site initiation visits. Regular on-site monitoring visits are planned at all sites depending on the recruitment rate and quality of the data (approximately one visit per site and year). The investigator must allow the monitor to look at all essential documents and must provide support at all times to the monitor. For all subjects clinical source data verification (SDV) for all clinical items is planned. The extent of further SDV and/or the frequency of monitoringvisits will be adapted for individual centers in case of bad quality of data or if common protocol violations are observed. In return, frequency of monitoring visits can be reduced for reliable and compliant centers with high data quality. In addition to the SOPs all procedures will be predefined in a study-specific monitoring manual. Queries (for example, in case of missing values, implausibility, et cetera) have to be answered by the investigators in a timely manner in order to avoid that errors in data capture or entry are held on to.

\section{Data and safety monitoring board (DSMB)}

To enable an independent risk assessment for the different surgical procedures, potentially related serious adverse events will be noted and periodically assessed by the independent Data and Safety Monitoring Board (DSMB). Detailed working procedures are defined in a different document.

\section{Steering committee}

An independent steering committee will be established. The steering committee will supervise the conduct of the trial and will issue recommendations for early termination, modifications or continuation of the trial, if necessary. The steering committee must be informed in a timely manner of SAE.

\section{Ethical and legal aspects}

Before the start of the trial, the trial protocol, informed consent document, and any other trial documents were submitted to the independent ethics committee.

The realization of this trial is ethically justifiable since both surgical techniques are routinely used. Studyspecific medical interventions exceeding this routine are not planned. Regarding the benefit/risk ratio of this trial for patients, no ethical objections for the realization should exist.

The procedures set out in the trial protocol, pertaining to the conduct, evaluation, and documentation of this trial, are designed to ensure that all persons involved in the trial abide by Good Clinical Practice (GCP) and the ethical principles described in the current revision of the Declaration of Helsinki. The trial will be carried out in keeping with local legal and regulatory requirements.

\section{Benefit-risk assessment}

Benefit-risk assessment will be critically reviewed and has to be approved by the ethics committees in advance before first recruitment.

All interventions applied in this trial represent clinically established, standard methods of treating fullthickness rectal prolapse. Therefore the applicants do not anticipate any serious adverse event that might be triggered due to the patient's participation in the trial itself.

\section{Discussion}

An evidence-based optimal surgical treatment for all patients with rectal prolapse does not exist [30]. Currently, there is no valid evidence as no conclusive data are yet available from larger randomized or even adequately casecontrolled studies. Perineal approaches, such as the Delorme's procedure, are deemed less invasive compared to abdominal procedures. Further advantages are shorter intervention time and the possibility to perform the operation under spinal or epidural anesthesia. On the other hand, the recurrence rates after such an approach are thought to be significantly higher than after an abdominal approach.

A prospectively randomized, adequately powered trial comparing these two established operation techniques with prolapse recurrence as primary outcome has never been successfully completed. In addition, trial registers of ongoing prospective studies do not indicate that there currently is a recruiting trial investigating this question (last search October 7, 2011).

An updated Cochrane review of Tou et al. [18] could only include one RCT comparing a perineal to an abdominal approach in a single center setting with a sample size of 20 and a median follow-up period of 17 months. In this study only one recurrence occurred in the perineal group 
[31]. An urgent need for high quality randomized clinical trials with adequate statistical power, long-term follow-up, and quality of life assessment is concluded by the authors and reference is made to the PROSPER Trial still ongoing at the time of the Cochrane review update.

The so-called PROSPER Trial in the United Kingdom [32] compared abdominal to perineal surgical approaches for rectal prolapse in a pragmatic two-stage randomization trial design depending on the surgeons degree of uncertainty which of four approaches to choose. The study was able to recruit 293 patients from 33 centers over a 7-year period from February 2001 up to the cessation of the trial in August 2008, but only 26 patients were actually randomized to one of the two approaches (last available newsletter from December 2005, see trial website). All other patients were allocated to one of the two procedures by surgeon's preference. In view of the very small number of patients actually randomized to a perineal versus an abdominal approach, the conclusions of this study are going to be very limited and the risk of selection bias is high. In addition, the majority of recruiting centers recruited less than 10 patients to the study, further reducing the validity of the results.

Considering the lessons learned from the PROSPER Trial, an urgent need currently exists for an adequately powered, simple parallel-group randomized trial comparing the abdominal to the perineal approach in rectal prolapse. Contrarily to the PROSPER Trial, clinical equipoise regarding the two surgical approaches has been concluded after extensive discussion of the available data as the confidence intervals of the published studies on the two approaches overlap considerably. Even if the study shows that the abdominal procedure results in significantly less recurrences this may be outweighed by a considerably higher morbidity and possibly less improved quality of life. This trial therefore only allows randomization to a perineal or abdominal approach. A loss of eligible patients to an observational non-randomized arm, as was the case for the majority of patients in the PROSPER Trial, will not be possible.

This trial is designed as an expertise-based trial aiming at strong internal validity by high performance and standardization. Generalizability may be reduced by the expertise-based trial design. However, this type of surgery in larger numbers is predominantly performed by specialized surgeons. For these surgeons but also for general surgeons operating only on a few cases per year the results of this trial should have an important impact on clinical practice by determining the most effective treatment for rectal prolapse.

In summary, considering the scarce high-level evidence available up to date we hope that our trial will add the necessary and confirmatory data to analyze which surgical approach is indeed superior.

\section{Trial status}

Recruitment is running since September 2010. All study centers have been initiated. As of March 2012, 186 patients have been screened. As of June 2012, 34 patients have been randomized.

\section{Competing interests}

The authors declare that they have no competing interests.

\section{Authors' contributions}

SR, FH, PK, SP, AH, and AJ designed and planned the DeloRes Trial. PS and MK supervised the statistical background of the DeloRes Trial. SR, FH, PS, and PK wrote the manuscript. All authors read and approved the final manuscript.

\section{Acknowledgements}

A Fuerst, MD, Department of Surgery, St. Josef's Hospital Regensburg, Germany; Th Schiedeck, MD, Department of Surgery, City Hospital Ludwigsburg, Germany; A Ommer, MD, MK Walz, MD, Department of Surgery, Hospital Essen Mitte, Germany; E. Berg, MD, Department of Coloproctology, Prosper Hospital Recklinghausen, Germany; H-P. Bruch, MD, U-J Roblick, MD, Department of General Surgery, University Medical Centre Luebeck, Germany; M Strik, MD, Department of Surgery, Helios Hospital Berlin-Buch, Germany; A Koehler, MD, Department of Coloproctology, St. Barbara Hospital Duisburg, Germany; F Hetzer, MD, Department of Surgery, Hospital of Canton Schaffhausen, Switzerland; D Hahnloser, MD, Department of Surgery, University Medical Centre Zuerich, Switzerland; L Duschka, MD, Department of Surgery/Coloproctology, German Hospital of Diagnostics Wiesbaden, Germany; N Demartines, MD, Department of Surgery, University Medical Centre Lausanne, Switzerland; R Ruppert, Department of Surgery, Hospital Munich Neuperlach, Germany as members of the DeloRes Study Group.

\section{Author details}

'Department of Surgery|, University Medical Centre Mannheim (UMM), University of Heidelberg, Heidelberg, Germany. ${ }^{2}$ Institute of Proctology Mannheim (EDZ), Mannheim, Germany. ${ }^{3}$ Institute of Medical Biometry and Informatics, University of Heidelberg, Heidelberg, Germany. ${ }^{4}$ Study Centre of the German Surgical Society, University of Heidelberg, Heidelberg, Germany.

Received: 20 December 2011 Accepted: 14 August 2012

Published: 29 August 2012

\section{References}

1. Ashari LH, Lumley JW, Stevenson AR, Stitz RW: Laparoscopically-assisted resection rectopexy for rectal prolapse: ten years' experience. Dis Colon Rectum 2005, 48:982-987.

2. Watts AM, Thompson MR: Evaluation of Delorme's procedure as a treatment for full-thickness rectal prolapse. Br J Surg 2000, 87:218-222.

3. Bruch HP, Herold A, Schiedeck T, Schwandner O: Laparoscopic surgery for rectal prolapse and outlet obstruction. Dis Colon Rectum 1999, 42:1189-1194.

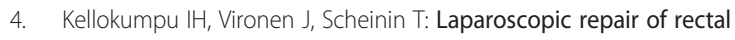
prolapse: a prospective study evaluating surgical outcome and changes in symptoms and bowel function. Surg EndosC 2000, 14:634-640.

5. Lechaux JP, Lechaux D, Perez M: Results of Delorme's procedure for rectal prolapse. Advantages of a modified technique. Dis Colon Rectum 1995, 38:301-307.

6. Marchal F, Bresler L, Ayav A, Zarnegar R, Brunaud L, Duchamp C, Boissel P: Long-term results of Delorme's procedure and Orr-Loygue rectopexy to treat complete rectal prolapse. Dis Colon Rectum 2005, 48:1785-1790.

7. Kariv Y, Delaney CP, Casillas S, Hammel J, Nocero J, Bast J, Brady K, Fazio WW, Senagore AJ: Long-term outcome after laparoscopic and open surgery for rectal prolapse: a case-control study. Surg Endosc 2006, 20:35-42.

8. Tsunoda A, Yasuda N, Yokoyama N, Kamiyama G, Kusano M: Delorme's procedure for rectal prolapse: clinical and physiological analysis. Dis Colon Rectum 2003, 46:1260-1265. 
9. Oliver GC, Vachon D, Eisenstat TE, Rubin RJ, Salvati EP: Delorme's procedure for complete rectal prolapse in severely debilitated patients. An analysis of 41 cases. Dis Colon Rectum 1994, 37:461-467.

10. Jorge JM, Wexner SD: Etiology and management of fecal incontinence. Dis Colon Rectum 1993, 36:77-97.

11. Tobin SA, Scott IH: Delorme operation for rectal prolapse. Br J Surg 1994 $81: 1681-1684$

12. Watkins BP, Landercasper J, Belzer GE, Rechner P, Knudson R, Bintz M, Lambert P: Long-term follow-up of the modified Delorme procedure for rectal prolapse. Arch Surg 2003, 138:498-502.

13. Pescatori M, Interisano A, Stolfi VM, Zoffoli M: Delorme's operation and sphincteroplasty for rectal prolapse and fecal incontinence. Int J Colorectal Dis 1998, 13:223-227.

14. Stevenson AR, Stitz RW, Lumley JW: Laparoscopic-assisted resection-rectopexy for rectal prolapse: early and medium follow-up. Dis Colon Rectum 1998, 41:46-54.

15. Kuhry E, Schwenk W, Gaupset R, Romild U, Bonjer J: Long-term outcome of laparoscopic surgery for colorectal cancer: a cochrane systematic review of randomised controlled trials. Cancer Treat Rev 2008, 34:498-504.

16. Sajid M, Siddiqui M, Baig M: Open vs laparoscopic repair of full-thickness rectal prolapse: a re-meta-analysis. Colorectal Dis 2009, 13:515525.

17. Sammour T, Kahokehr A, Srinivasa S, Bissett IP, Hill AG: Laparoscopic colorectal surgery is associated with a higher intraoperative complication rate than open surgery. Ann Surg 2011, 253:35-43.

18. Tou S, Brown SR, Malik Al, Nelson RL: Surgery for complete rectal prolapse in adults. Cochrane Database Syst Rev 2008, 8:CD001758.

19. Dindo D, Demartines N, Clavien PA: Classification of Surgical complications: A new Proposal with evaluation in a cohort of 6336 Patients and results of a survey. Ann Surg 2004, 240:205-213.

20. Rahbari NN, Weitz J, Hohenberger W, Heald RJ, Moran B, Ulrich A, Holm T, Wong WD, Tiret E, Moriya Y, Laurberg S, den Dulk M, van de Velde C, Büchler MW: Definition and grading of anastomotic leakage following anterior resection of the rectum: a proposal by the International Study Group of Rectal Cancer. Surgery 2010, 147:339-351.

21. Horan TC, Gaynes RP, Martone WJ, Jarvis WR, Emori TG: CDC definitions of nosocomial surgical site infections, 1992: a modification of CDC definitions of surgical wound infections. Infect Control Hosp Epidemiol 1992, 13:606-608.

22. Ware J Jr, Kosinski M, Keller SD: A 12-Item Short-Form Health Survey: construction of scales and preliminary tests of reliability and validity. Med Care 1996, 34:220-233.

23. Braun M, Herold A, Krammer H, Schlieger F: Evaluierung eines Scores zur Unterscheidung verschiedener Obstipationsformen. Coloproctology 2006, 28.

24. Rockwood TH, Church JM, Fleshman JW, Kane RL, Mavrantonis C, Thorson AG, Wexner SD, Bliss D, Lowry AC: Patient and surgeon ranking of the severity of symptoms associated with fecal incontinence: the fecal incontinence severity index. Dis Colon Rectum 1999, 42:1525-1532.

25. Senapati A, Nicholls RJ, Thomson JP, Phillips RK: Results of Delorme's procedure for rectal prolapse. Dis Colon Rectum 1994, 37:456-460.

26. Kim DS, Tsang CB, Wong WD, Lowry AC, Goldberg SM, Madoff RD: Complete rectal prolapse: evolution of management and results. Dis Colon Rectum 1999, 42:460-466.

27. Carpelan-Holmström M, Kruuna O, Scheinin T: Laparoscopic rectal prolapse surgery combined with short hospital stay is safe in elderly and debilitated patients. Surg Endosc 2006, 20:1353-1359.

28. Huber FT, Stein H, Siewert JR: Functional results after treatment of rectal prolapse with rectopexy and sigmoid resection. World I Surg 1995, 19:138-143.

29. nQuery Advisor ${ }^{\circledR}$ Release 7.0. Statistical Solutions. Saugus: http://www.statisticalsolutions-software.com/products-page/nquery-advisor-sample-size-software.

30. Schiedeck TH, Schwandner O, Scheele J, Farke S, Bruch HP: Rectal prolapse: which surgical option is appropriate? Langenbecks Arch Surg 2005, 390:8-14.

31. Deen $\mathrm{Kl}$, Grant E, Billingham C, Keighley MRB: Abdominal resection rectopexy with pelvic floor repair versus perianal rectosigmoidectomy and pelvic floor repair for full-thickness rectal prolapse. Br J Surg 1994, 81:302-304.

32. PROSPER - PROlapse Surgery PErineal or Rectopexy: http://www.prosper.bham. ac.uk.

doi:10.1186/1745-6215-13-155

Cite this article as: Rothenhoefer et al:: DeloRes trial: study protocol for a randomized trial comparing two standardized surgical approaches in rectal prolapse - Delorme's procedure versus resection rectopexy. Trials 2012 13:155

\section{Submit your next manuscript to BioMed Central and take full advantage of:}

- Convenient online submission

- Thorough peer review

- No space constraints or color figure charges

- Immediate publication on acceptance

- Inclusion in PubMed, CAS, Scopus and Google Scholar

- Research which is freely available for redistribution 